\title{
Unmanned aerial systems for agriculture and natural resources
}

Sean D. Hogan, Drone Service Coordinator, Informatics and GIS Statewide Program, UC Agriculture and Natural Resources

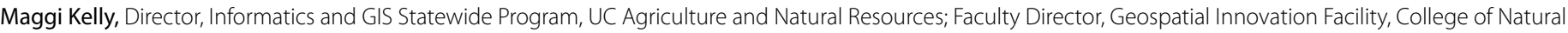
Resources, UC Berkeley; Professor and UC Cooperative Extension Specialist, Department of Environmental Sciences, Policy and Management, UC Berkeley

Brandon Stark, Director of the Center of Excellence on Unmanned Aircraft System Safety, UC Merced and UC Office of the President

YangQuan Chen, Director, Mechatronics, Embedded Systems and Automation (MESA) Lab, UC Merced

S

mall unmanned aerial systems (UAS), also known as drones or unmanned aerial vehicles, have a rapidly growing role in research and practice in agriculture and natural resources. Here, we present the parameters and key limitations of the technology, summarize current regulations and cover examples of University of California research enabled by UAS technology.

Motorized UAS were introduced as a potential remote sensing tool for scientific research in the late 1970s. However, due to a variety of limitations (the weight and limited functionality of available sensors and cameras, the lack of GPS-guided autopilots and so on) these platforms

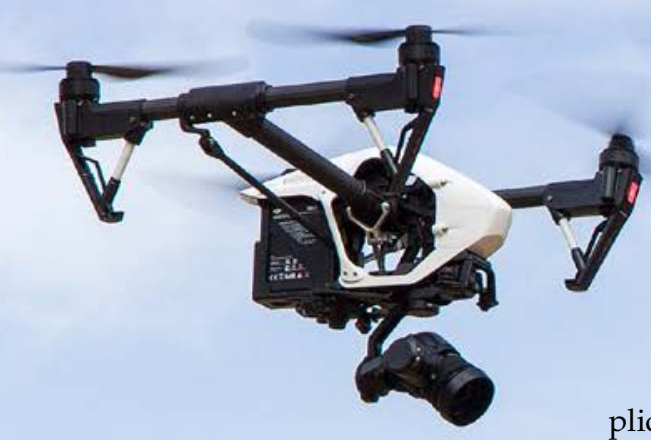
had few practical applications (Przybilla and Wester-Ebbinghaus 1979; WesterEbbinghaus 1980; cited by Colomina and Molina 2014).

For years, UAS technology was led by military needs and applications. The relatively few applications in research and agriculture included deployments in Japan for crop dusting and in Australia for meteorological studies (Colomina and Molina 2014).

In the past decade, several factors have greatly increased the utility and ease of use of UAS, while prices have fallen. Consumer demand drove the hobby craft industry to make major improvements in UAS vehicles. Integrating improved battery technology, miniature inertia measurement units (IMU, initially developed for smartphones), GPS and customizable apps for smartphones and tablets has delivered improved flight longevity, reliability, ease of use and the ability to better utilize cameras and other sensors needed for applications in agriculture and natural resources (see below, Types of UAS). Innovations in sensor technology now include dozens of models of lightweight visible-spectrum and multispectrum cameras capable of capturing reliable, scientifically valid data from UAS platforms (see UAS sensors) (Whitehead and Hugenholtz 2014). Meanwhile, the Federal Aviation Administration (FAA) has helped facilitate increased UAS use, with rule changes adopted in August 2016 that lowered what have previously been significant regulatory obstacles to the legal use of UAS for research and commercial purposes (see Regulations sidebar).

UC faculty throughout California are using UAS in a wide range of agricultural and environmental research projects - from grazed rangelands to field crops and orchards, forests, lakes and even the ice sheets of Greenland

The Inspire 1 drone, made by DJ, flies with an RGB camera over th UC Berkeley Blue Oak Ranch Reserve in Santa Clara County.

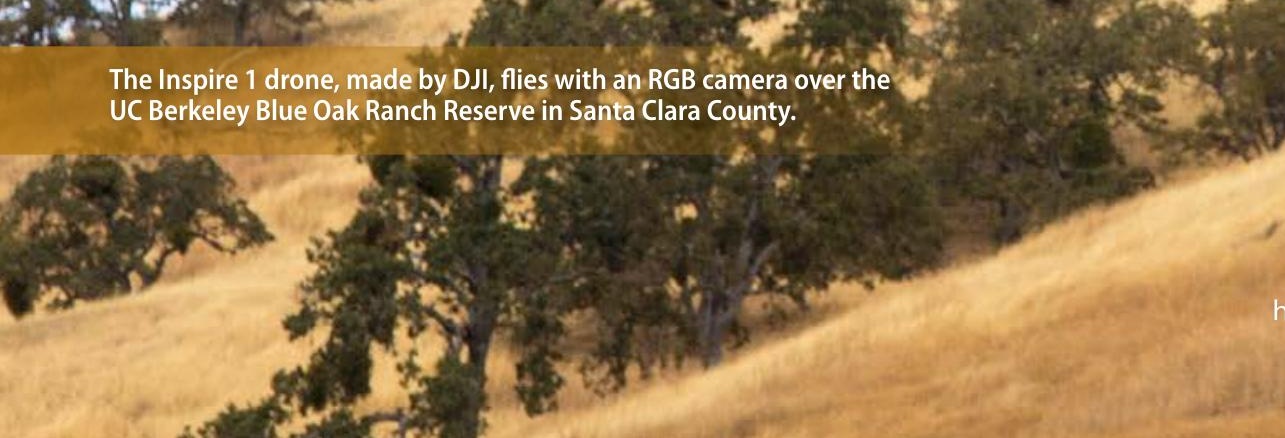




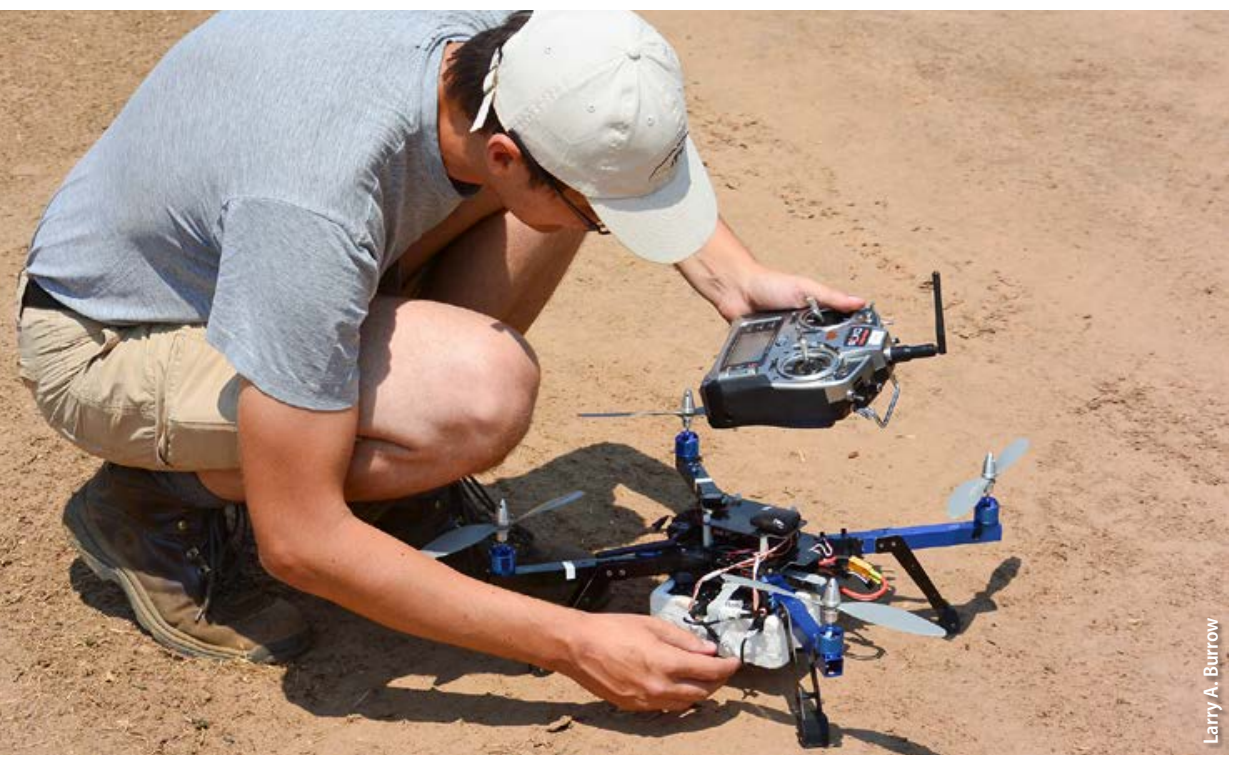

Andreas Anderson, an instructor with the Center for Information Technology Research in the Interest of Society at UC Merced, checks the control systems for a drone-mounted multispectral camera before a research flight in Merced County for a study on water stress in almond trees. (see below, Research case studies). UAS also have become a part of the curriculum across the UC system, and are increasingly used by campus staff in departments from facilities to athletics to marketing (see UAS at UC sidebar).

UAS are already in wide use in agriculture, and the sector is projected to continue to account for a large share $-19 \%$ in the near term, per a recent FAA report (FAA 2016a) - of the commercial UAS market in the United States. The use of UAS for research, particularly remote sensing and mapping, is soaring: A search in Scopus (2016) finds 3,079 articles focused on UAS or UAV applications in 2015, compared with 769 in 2005. Across all commercial uses, the FAA estimates 2016 sales of commercial UAS (including those used for research purposes) at 600,000 units and expects that figure to balloon to 2.5 million units annually as soon as 2017 (FAA 2016a).

\section{Regulations}

T he U.S. Federal Aviation Administration (FAA) provides guidance and regulation for U.S. airspace. The agency has adopted different rules for recreational and nonrecreational uses of UAS.

The recreational use of UAS is regulated by Title 14, Part 101 of the Code of Federal Regulations commonly known as the "model aircraft" regulations. These regulations apply only if the operator is not compensated in any way for the UAS operation, and if the flight is not incidental to a business purpose regardless of compensation (so, for instance, farming-related uses of UAS do not count as recreational, even if the UAS is operated by the grower or a farm employee). Recreational UAS operators are not required to have a license, and must comply only with basic safety rules such as:

- Fly at or below 400 feet

- Keep your UAS within sight

- Never fly near other aircraft, especially near airports

- Never fly over groups of people

- Never fly over stadiums or sports events

- Never fly near emergency response efforts such as fires

- Never fly under the influence

- Be aware of airspace requirements (FAA 2016b)

Nonrecreational use - defined as deployment of a UAS for any type of "work, business purposes, or for compensation or hire" (FAA 2016c) - falls under a different set of rules, those for "small unmanned aircraft" of up to 55 pounds: Title 14, Part 107 of the Code of Federal Regulations. These rules were updated in several important ways in August 2016.

Previously, the only legal way to fly a UAS for nonrecreational use was with a FAA Certificate of Authorization (COA) for each aircraft issued under Section 333 of the FAA Modernization and
Reform Act of 2012 (FAA 2016d). Obtaining a COA was difficult (often requiring the operator to hold a pilot's license for manned aircraft) and time-consuming, requiring abundant documentation followed by FAA processing times of several months. Once a COA was granted, the pilot was typically required to file a notice to airmen (NOTAM) with the FAA prior to every flight; many businesses and institutions were hesitant to authorize flights due to concerns of liability, given the absence of standardized safety guidelines.

The new rules eliminate the need for a manned pilot's license, replacing it with a requirement that nonrecreational operators hold a newly created type of license specifically for UAS operation. This license is obtained after passing an "Unmanned Aircraft General" aeronautical knowledge test at an FAA-approved knowledge testing center (the test fee is \$150). The FAA estimates that the average applicant will spend 20 hours for self-study in preparation for the two-hour exam, and anticipates that $90 \%$ of applicants will pass the exam on the first try. By comparison, obtaining a manned pilot's license costs thousands of dollars for instruction, in-flight-training and exam fees. In addition, the new rules create a simple online registration process for commercial and research UAS ( $\$ 5$ per UAS) (FAA 2016e).

The FAA does not generally require logging of flight data on a per flight basis, unless operating under a specific waiver (e.g., nighttime flight, under terms that will specified in that specific waiver). Per flight logging and reporting is required for UC-affiliated researchers, who must submit flight information to the UC Center of Excellence for Unmanned Aircraft Systems Safety for the UC to track its UAS operations (ehs.ucop.edu/drones).

The full list of rules governing UAS flight for research and commercial purposes is provided on the FAA website. 
Despite the growing ubiquity of UAS, a variety of practi$\mathrm{cal}$ and scientific challenges remain to using the technology effectively.

Collecting and processing data that is useful for management decisions requires a disparate range of skills and knowledge - understanding the relevant regulations, determining what sensing technology and UAS to use for the problem at hand, developing a data collection plan, safely piloting the UAS, managing the large data sets generated by the sensors, selecting and then using the appropriate image-processing and mapping software, and interpreting the data.

In addition, as highlighted in the research cases presented below, much science remains to be done to develop reliable methods for interpreting and processing the data gathered by UAS sensors, so that a user can know with confidence that the changes or patterns detected by a UAS camera reflect reality.

The UC Agriculture and Natural Resources (ANR) Informatics and GIS (IGIS) program has recently incorporated drone services into the portfolio of support that it offers to UC ANR and its affiliated UC Agricultural Experiment Station faculty. You can find out more about these services and UC affiliates can submit service requests via the IGIS website, igis.ucanr.edu. Working closely with UC Office of the President, Center of Excellence on Unmanned Aircraft System Safety (UCOP 2016), IGIS has also developed a workshop curriculum around UAS technology, regulations and data processing, which is open to members of the UC system as well as the public. Please check the IGIS website to learn about upcoming training events around the state in 2017, including a three day "DroneCamp" that will intensively cover drone technology, regulations and data processing.

\section{UAS at UC}

Uñ AS are becoming part of the standard curriculum across the UC system, helping to prepare students to plug into a sector that is expected to generate thousands of new jobs in the coming years (more than 12,000 by 2017 in California alone, per a 2013 study (AUVSI 2013)). Here are several examples:

- UC Berkeley: Electrical Engineering and Computer Science 98/198, Unmanned Aerial Vehicles Flight Control and Assembly

- UC Davis: Aerospace Science and Engineering 10, Drones and Quadcopters; Geography 298, Environmental Monitoring and Research with Small UAS

- UC Irvine: Engineering 7, Introduction to Engineering

- UCLA: Architecture and Urban Design students fly drones to collect images that are used to create 3-D visualizations of projects

- UC Merced: Mechanical Engineering 190, Unmanned Aerial Systems

- UC San Diego: Course credit for competing in the American Institute of Aeronautics and Astronautics (AIAA) Design, Build, Fly competition
- UC Agriculture and Natural Resources: The IGIS program provides workshops on UAS technology and regulations across California in collaboration with the UC Berkeley Geospatial Innovation Facility that are UC oriented but also open to the public (igis.ucanr.edu/IGISTraining)

Campus staff, too, are using UAS in a wide range of applications - from monitoring construction projects and inspecting buildings to shooting video for marketing and sports programs.

Changes in August 2016 to the federal regulations governing UAS operation (see Regulations sidebar) make it far easier to legally operate a UAS for nonrecreational purposes. Based on anecdotal information tracked by the UC Center of Excellence on Unmanned Aircraft System Safety, UAS use has grown dramatically across multiple UC campuses in the few months since the adoption of the new rules. 


\section{Unmanned aerial systems and the sensors they carry}

\section{Types of UAS}

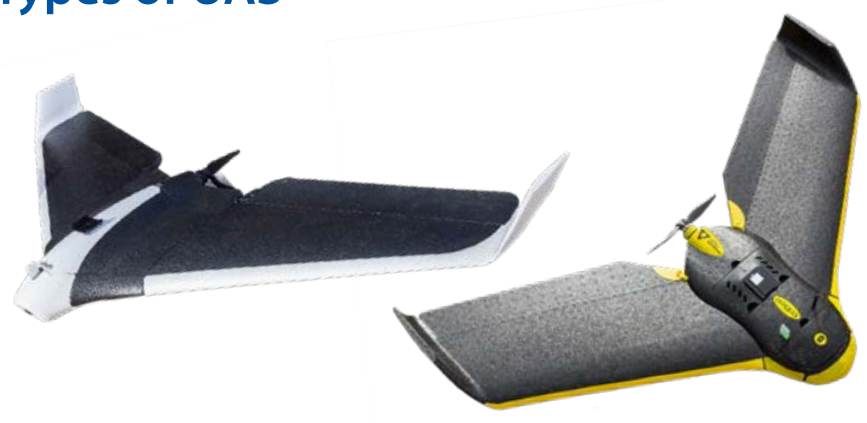

Fixed-wing

Advantages: A fixed-wing aircraft generates lift as it moves through the air, meaning that the propeller doesn't have to do all the work of keeping it aloft. Thus, fixed-wing UAS typically have larger payload capacity, higher top speed, longer flight times and longer range compared to rotor systems with similar battery capacity. For these reasons, fixed-wing systems are particularly useful for collecting data over a large area.

Disadvantages: Compared to rotor UAS, fixed-wing systems are less maneuverable, require more open space for landing and more skill to pilot, and tend to be several times more expensive than similar-grade rotor systems.

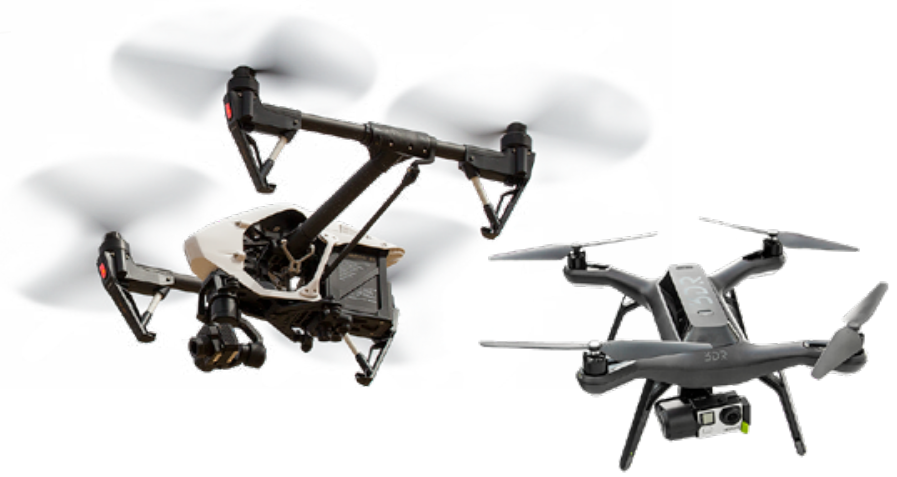

Rotor

Advantages: Rotorcraft are highly maneuverable, with the ability to hover, rotate and capture images at almost any angle. Manual takeoff, flying and landing are easy to learn, and some models have built-in "sense-and-avoid" technology. There are many low-cost models on the market, along with more costly units with larger payload capacity and/or flight time.

Disadvantages: Shorter range and flight time compared to similar-grade fixed-wing UAS are the main drawbacks to rotorcraft.

\section{UAS sensors}

(2)

\section{Description}

\section{Typical applications}

\section{Image example}

\section{Other considerations}

\section{RGB digital camera}

Captures visible-spectrum (red, green and blue, or RGB) photographs or video between 390 and 700 nanometers in wavelength

Creation of true color orthomosaics (composite images of a large area), topographic modeling using photogrammetry, and 3-D visualization

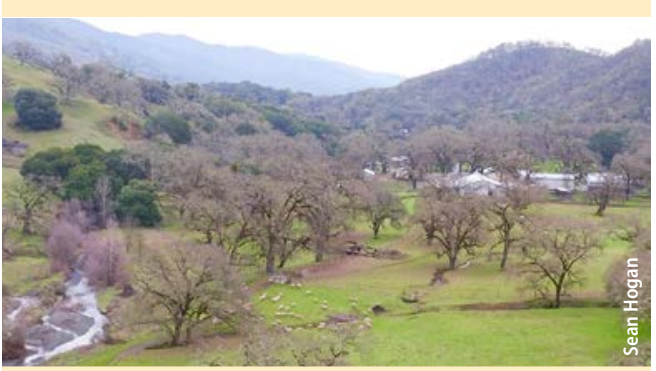

Photogrammetry can be used to model elevation at a spatial resolution similar to that of the processed image pixel resolution. Visible-spectrum photogrammetry is not effective for mapping belowcanopy vegetation and ground elevation.

\section{Thermal camera}

Captures thermal images or video in the longinfrared range, roughly 7,000 to 12,000 nanometers

Monitoring relative surface temperatures to provide information on, for instance, water features, wildlife, evapotranspiration and soil moisture content.

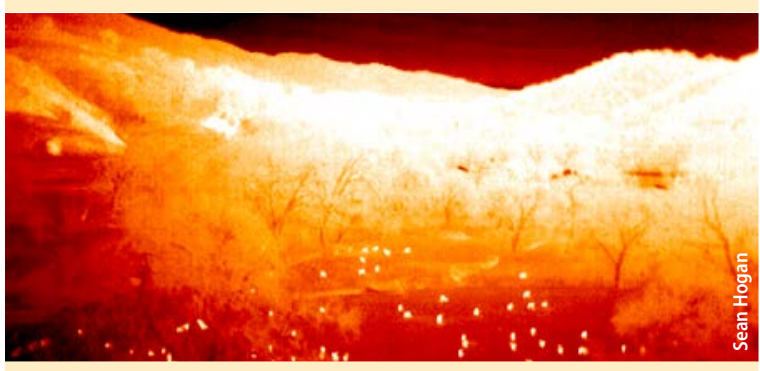

Generally not suitable for photogrammetry due to lack of sharp contrast

The type of sensor that a UAS can carry is determined by the UAS's designed payload capacity. Any type of instrument may be used as long as it's light enough for a given UAS platform. Most conventional UAS have a maximum payload between 300 and 1,500 grams (0.66 to 3.3 pounds). There is a tradeoff between instrument payload and fight time, especially for rotorcraft. 
in how the canopy reflects near-infrared light. This project is building a database of canopy spectral signatures and water-stress measurements with the objective of developing indices that can be used to reliably translate UAS imagery into useful water-stress information.

In a related experiment, Zhao is working with Dong Wang of the USDA Agriculture Research Service (ARS) San Joaquin Valley Agricultural
Sciences Center to detect the effects of varying irrigation levels and biomass soil amendments on crop development and yield in onions. As in Zhao's almond experiment, the researchers are comparing spectral signatures gathered by low-cost UAS-mounted multispectral cameras with ground-truth data to better understand the relationship between the two (Tiebiao Zhao, UC Merced, mechatronics.ucmerced.edu).
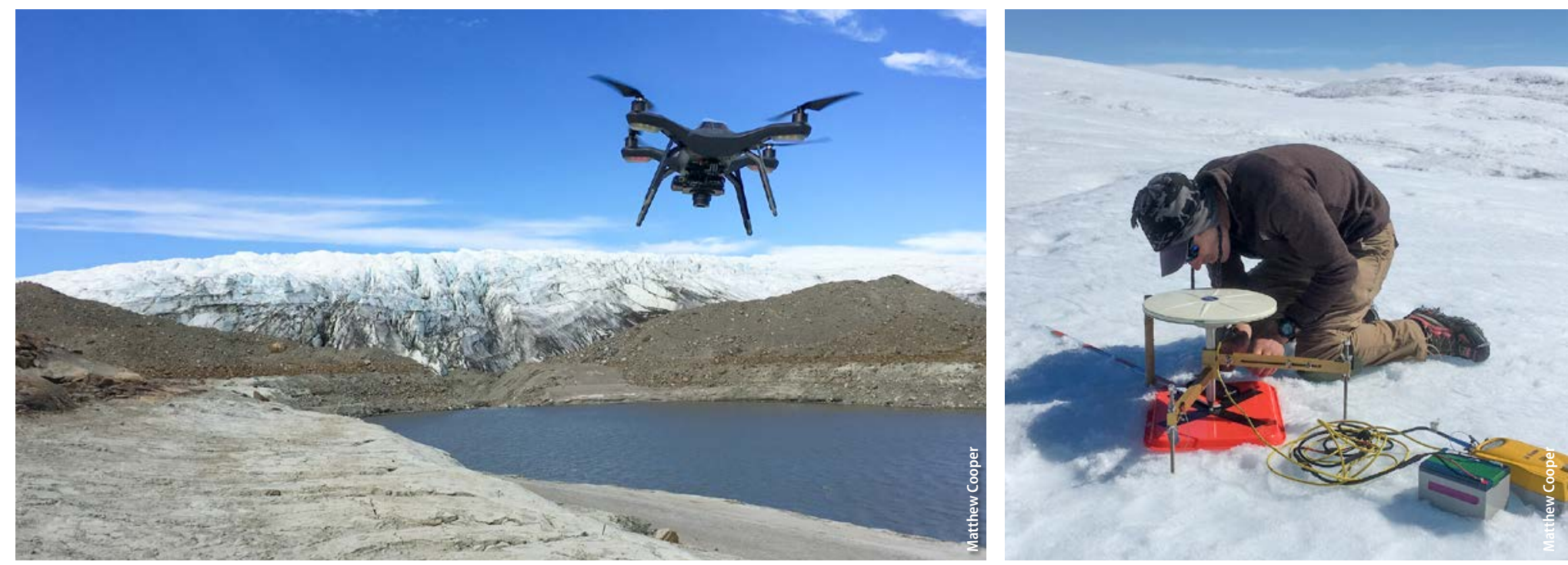

\section{Natural resources}

\section{Mapping the Greenland ice sheet}

The Greenland ice sheet covers 656,000 square miles and holds roughly 2.3 trillion acre-feet of water - the sea level equivalent of 24 feet. As the climate warms, ice sheet melt accelerates; therefore, understanding the processes involved is important. This knowledge can help to refine predictions about the ice sheet's future and its contribution to global sea level rise.

A team of researchers led by UCLA professor of geography Laurence Smith is using UAS-based imaging technologies to map and monitor meltwater generation, transport and export. The group's UAS carry multiband visible and near-infrared digital cameras that capture sub-meter resolution data, from which the researchers create multiple orthomosaics of the ice surface and perimeter over time. They are using the data to analyze a number of different cryohydrologic processes and features, including mapping rivers on the ice surface from their origins to their termination at moulins - vertical conduits that connect the ice surface with en- and sub-glacial drainage networks and meltwater outflow to the ocean. The team is also generating digital elevation models of the ice surface
Above left, a 3D Robotics Solo drone carrying a Canon point-and-shoot camera flies a mapping mission over a lake in western Greenland the day after a jökulhlaup (a glacial outburst flood). Above right, precise ground control point surveys are needed to accurately geolocate imagery collected with a drone and produce high quality orthomosaics. The photo shows Rutgers University doctoral student Sasha Leidman conducting a differential GPS survey of a ground control marker on the Greenland ice sheet.

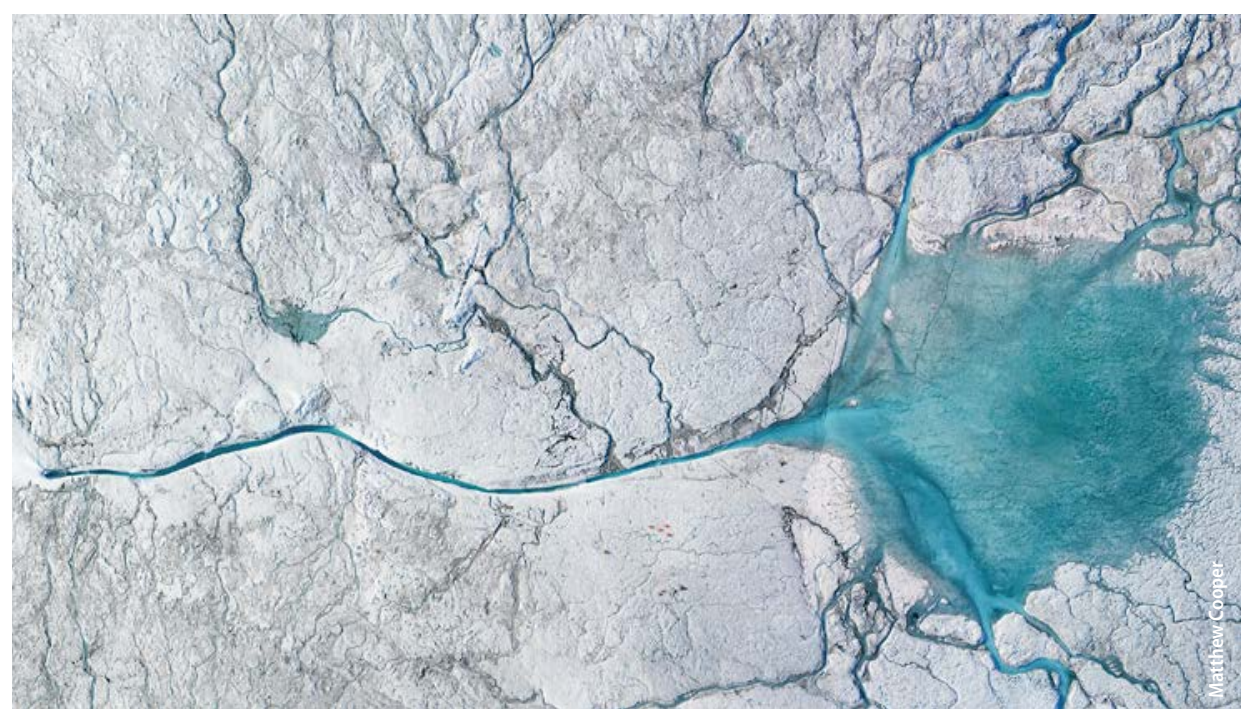

To monitor meltwater fluxes across the surface of the Greenland ice sheet, researchers generated orthomosaics like this one from digital imagery shot by a Canon point-andshoot camera mounted on a 3D Robotics Solo drone. 
are being used to "teach" image-analysis software — via what's known as a machine-learning algorithm — how the spectral signatures of goatgrass and yellow star thistle differ from those of forage species at various times of year.

- Cattle manure is a common source of bacterial contamination in California waterways. UAS imagery may enable precise mapping of the location and volume of manure deposits on the landscape. Such data could then inform models that predict likely fecal coliform loading in nearby streams.

- Photographic imagery collected by UAS may enable estimates of forage production by measuring changes in grass height over time. The research team is comparing ground-level measurements of vegetation height with the results of digital surface models - very high-resolution topographic maps - generated from images captured by UAS-mounted cameras. The image-processing software uses a photogrammetric approach, which analyzes multiple overlapping images to generate precise elevation maps (Sean Hogan, UC ANR, igis.ucanr.edu). CA

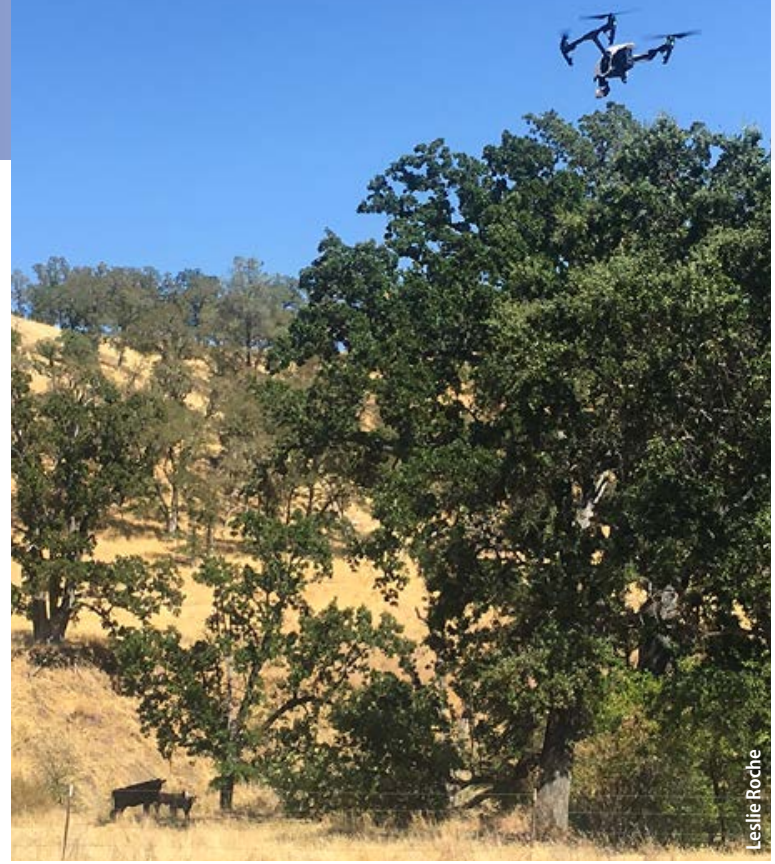

A DJI Inspire 1 drone flies over cattle for a rangeland ecology study at Gamble Ranch in Napa County.
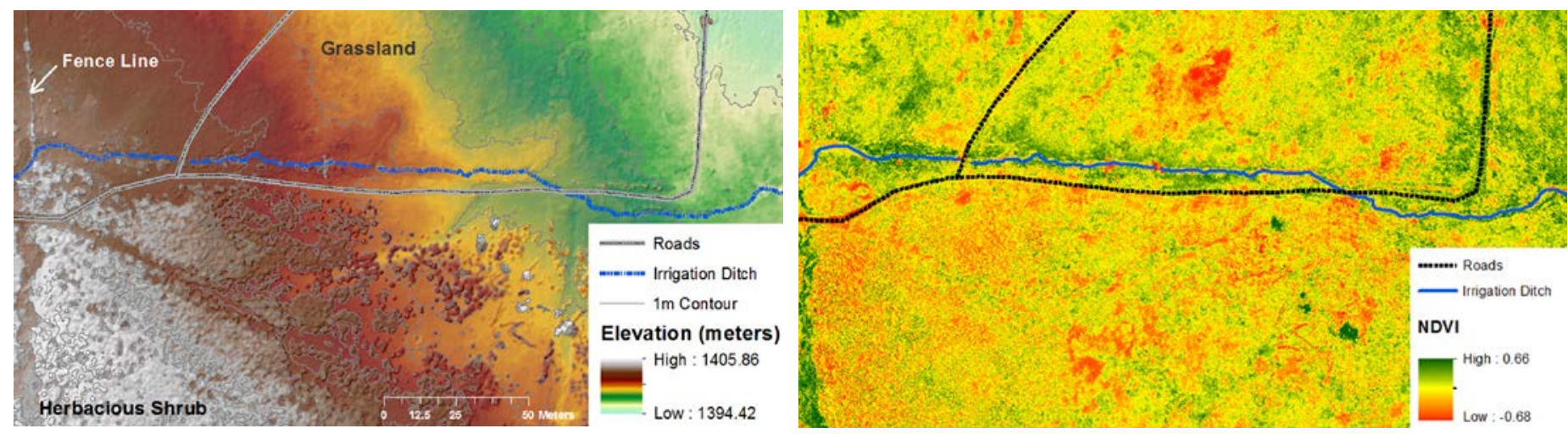

High-resolution imagery gathered from a drone can be used to assess rangeland condition and forage production. The above images show 12 acres of rangeland in Inyo County. The image at left is a digital surface model (DSM) with a resolution of 0.8 inches, generated from digital photographs. Fine resolution DSMs like this can be used over time to monitor vegetation growth, and hence forage production. The image at right, captured by a Parrot Sequoia multispectral camera, shows the normalized difference vegetation index (NDVI) at a resolution of 1.45 inches. The NDVI is a measure of the relative absorbance of near-infrared and visible light and can be used to distinguish green vegetation (shown in the image as green) from stressed, dying or dead vegetation (shown as yellow to red in the image).

\section{References}

[AUVSI] Association for Unmanned Vehicle Systems International. 2013. Economic Impact of Unmanned Aircraft Systems Integration in the United States. https://higherlogicdownload.s3.amazonaws.com/AUVSI/958c920a7f9b-4ad2-9807-f9a4e95d1ef1/Uploadedlmages/ New_Economic\%20Report\%202013\%20Full.pdf.

[CDF] California Department of Forestry and Fire Protection. 2008. The Changing California, Forest and Range Assessment 2003. Last updated Oct. 2003. www.frap.cdf. ca.gov/assessment2003/Chapter2_Area/rangelandarea. html (no longer active; last accessed June 11, 2008).

Chung M, Detweiler C, Hamilton M, et al. 2015. Obtaining the thermal structure of lakes from the air. Water 7(11):6467-82.

Colomina I, Molina P. 2014. Unmanned aerial systems for photogrammetry and remote sensing: A review. ISPRS Photogramm 92: 79-97.

[FAA] Federal Aviation Administration. 2016a. FAA Aerospace Forecast Fiscal Years 2016-2036. www.faa.gov/ data_research/aviation/aerospace_forecasts/media/ FY2016-36_FAA_Aerospace_Forecast.pdf.
FAA. 2016b. Request a waiver/airspace authorization small unmanned aircraft system (sUAS). www.faa.gov/ uas/request_waiver/.

FAA. 2016b. Flying for fun. www.faa.gov/uas/getting started/fly_for_fun/.

FAA. 2016c. Unmanned aircraft systems (UAS) frequently asked questions/help - Flying for fun (recreational or hobby). www.faa.gov/uas/faqs/\#ffr.

FAA. 2016d. Unmanned aircraft systems - section 333. www.faa.gov/uas/beyond_the_basics/section_333/. FAA. 2016e. sUAS Registration Service home page. https://registermyuas.faa.gov/.

Minařík R, Langhammer J. 2016. Use of a multispectral UAV photogrammetry for detection and tracking of forest disturbance dynamics. Int Arch Photogramm Remote Sens 41:711-18.

Przybilla H, Wester-Ebbinghaus W. 1979. Bildflug mit ferngelenktem Kleinflugzeug. Bildmessung und Luftbildwessen 47:137-142.

Ryan JC, Hubbard AL, Box JE, et al. 2015. UAV photogrammetry and structure from motion to assess calving dynamics at Store Glacier, a large outlet draining the Greenland ice sheet. Cryosphere 9(1):1-11.
Ryan JC, Hubbard AL, Stibal M, et al. 2016. Attribution of Greenland's ablating ice surfaces on ice sheet albedo using unmanned aerial systems. Cryosphere Discuss. doi:10.5194/tc-2016-204. In review.

Ryan JC, Hubbard AH, Box JE, et al. High resolution albedo products derived from digital camera images: UAV application over the K-sector of the Greenland ice sheet. In preparation.

Scopus. 2016. Document search results "Unmanned Aerial Vehicle". www.scopus.com/.

Six DL, Biber E, Long E. 2014. Management for mountain pine beetle outbreak suppression: Does relevant science support current policy? Forests 5(1):103-33.

[UCOP] University of California Office of the President. 2016. UC unmanned aircraft systems safety. www.ucop. edu/enterprise-risk-management/resources/centers-ofexcellence/unmanned-aircraft-systems-safety.html.

Wester-Ebbinghaus W. 1980. Aerial photography by radio controlled model helicopter. Photogramm Rec 10:85-92.

Whitehead K, Hugenholtz CH. 2014. Remote sensing of the environment with small unmanned aircraft systems (UASs), part 1: A review of progress and challenges. J Unmanned Vehicle Syst 2:69-85. 